\title{
Cryptococcal meningitis in Rio de Janeiro State, Brazil, 1994-2004
}

\author{
Meningite criptocócica no Estado do Rio de Janeiro, \\ Brasil, no período de 1994 a 2004
}

\footnotetext{
${ }_{1}$ Laboratório de Microbiologia/Micologia, Instituto Estadual de Infectologia São Sebastião, Rio de Janeiro, Brasil.

2 Escola Nacional de Saúde Pública Sergio Arouca, Fundação Oswaldo Cruz, Rio de Janeiro, Brasil.

Correspondence B. C. Q. Leimann Laboratório de Microbiologia/Micologia, Instituto Estadual de Infectologia São Sebastião. Rua Nascimento Silva 383, apto. 401, Rio de Janeiro, $R J$ 22421-020, Brasil.

leimann@centroin.com.br
}

\begin{abstract}
The objective of this article was to evaluate the epidemiology of cryptococcal meningitis in Rio de Janeiro State, Brazil, from 1994 to 2004. Six hundred and ninety-six cases of cryptococcal meningitis were reported, with a mean incidence of 0.45 per 100,000 inhabitants. Patients were predominantly male; mean age was 35.9 years; AIDS was practically the only underlying disease, reported in $61.2 \%$ of cases; case-fatality was 51.8\%. No decline in incidence was observed during the study period. AIDS is the main predisposing condition for cryptococcal meningitis, and thus the profile of most patients mirrors that of HIV infection. Missing information prevented the evaluation of other underlying diseases.
\end{abstract}

Cryptococcal Meningitis; Incidence Rate; Epidemiologic Surveillance
Beatriz Consuelo Quinet Leimann 1 Rosalina Jorge Koifman 2

\section{Introduction}

The principal etiological agent of fungal meningitis in the world is an encapsulated yeast that presents two distinct species recognized in the Cryptococcus neoformans complex: C. neoformans and C. gattii 1,2. C. neoformans is distributed worldwide and predominantly affects immunocompromised individuals. $C$. gattii infection generally affects immunocompetent individuals and predominates in tropical and subtropical regions. The disease is endemic in Northeast Brazil, Paraguay, Mexico, Australia, several African countries, India, Southeast Asia, and California (USA) ${ }^{3}$. Due to the important tropism of this fungus for the central nervous system, meningitis is the principal clinical manifestation in some $85 \%$ of cases of cryptococcal infection 4,5 .

Until the late 1970s, cryptococcal disease was described in patients with underlying diseases like lymphoma, sarcoidosis, liver disease, and kidney transplant patients ${ }^{6}$, and was considered a rare condition. Beginning in the 1980s, with the emergence of HIV infection, cryptococcal disease acquired a relevant role as an opportunistic infection, with increasing morbidity and mortality rates 6,7. The use of prophylactic antifungals and the introduction of HAART (highly active antiretroviral therapy) in 1995-1996 modified the course of cryptococcal disease in HIV patients, with reductions in the incidence rates varying from $46 \%$ to $75 \% 7,8,9,10,11$. Despite a decrease in the num- 
ber of AIDS cases, HIV is still the principal risk factor for cryptococcosis. According to data from the Centers for Disease Control and Prevention (CDC), 85\% of cryptococcosis cases in the United State occurred in HIV patients 12 , while in France, Chrétien et al. 13 report $80 \%$. An estimated 5\% to $10 \%$ of HIV patients have cryptococcosis as their AIDS-defining disease 14 .

In addition to HIV infection, the principal predisposing conditions for cryptococcal disease are those that also involve cellular immunodeficiency, like treatment for hematological cancer, the use of immune suppressors in transplant patients, and prolonged corticosteroid therapy 5,15. Other conditions not related directly to cellular immunity, like diabetes, alcoholism, and sarcoidosis, are also defined as risk factors for cryptococcosis 16 .

In Brazil, Almeida \& Lacaz ${ }^{7}$ reported the first case of cryptococcosis in 1941. Oliveira-Netto et al. 4 , in a retrospective study of 302 cases of cryptococcosis published in the Brazilian literature from 1941 to 1992, reported that 179 (59.3\%) had occurred in the last 10 years. In $72 \%$ of the 153 patients with some diagnosed predisposing condition, the latter was AIDS. As elsewhere in the world, in Brazil the introduction of HAART in 1995-1996 and the use of prophylactic antifungals led to an important decrease in cryptococcosis incidence 7,9 .

There are few data on the epidemiology of cryptococcosis in the various States of Brazil. The published articles refer to single hospital-based studies that are complete 17,18 but do not reflect the profile of the disease in the general population.

In the State of Rio de Janeiro, Brazil, the available studies on cryptococcal meningitis were published in 198419 and 1994 20, and there is still no information on incidence temporal trends in the State or repercussions from the introduction of HAART for AIDS patients or as a result of the increase in the number of transplants.

The objective of the current study was to determine the epidemiological profile of cryptococcal meningitis in the State of Rio de Janeiro from 1994 to 2004 .

\section{Material and methods}

This was a descriptive exploratory study on the incidence of cryptococcal meningitis in the State of Rio de Janeiro from 1994 to 2004. Data on cryptococcal meningitis in the State are available in two databases: the Advisory Board on Meningitis, a division of the Epidemiological Surveillance Center of the Rio de Janeiro State Health Depart- ment, and in the Information System on Notifiable Diseases (SINAN). Both databases are fed by information from the "individual meningitis investigation form". This data collection instrument does not have a field with a specific code for cryptococcal meningitis, and the latter is recorded as open information in the field "meningitis of another etiology". Considering that the database of the Advisory Board on Meningitis covers a longer time period, we chose to use it as the data source.

The Advisory Board on Meningitis receives notifications of all meningitis cases from the $\mathrm{Mu}$ nicipal Health Departments and directly from the Epidemiological Surveillance Unit of the São Sebastião State Institute of Infectology (IEISS), which is the referral center for meningitis diagnosis in the State. Cases reported by the IEISS include both patients treated at the Institute itself and those whose cerebrospinal fluid (CSF) samples are collected at other units and analyzed at the IEISS laboratory.

The criterion adopted in this study for definition of an incident case was the first notification with diagnostic confirmation of cryptococcal meningitis present in the database during the period. Subsequent diagnoses for the same individual during the study were considered as relapse of cryptococcal meningitis.

The study variables were: age, gender, municipality (county) of residence, residential zone (rural versus urban), preexisting diseases, type of diagnostic confirmation (direct India ink test, CSF culture of Cryptococcus sp. or latex agglutination, clinical, therapeutic challenge, autopsy, death certificate), and type of evolution (categorized as discharge, death, or death from another cause). In relation to age, individuals under 20 years were stratified in two strata: $0-12$ and $13-19$ years. The first age bracket included children up to 12 years of age, in accordance with the national 21,22 and international literature 23 . To complement the information on preexisting diseases, AIDS notification data were accessed in the SINAN STD/AIDS database. Due to the high missing information rate, the race/color variable was not analyzed.

Excel and Access (Microsoft Corp., USA) and SPSS (SPSS Inc., Chicago, USA) were used for the data analysis. The proportions were compared using the chi-square test, means using the Student's t test, and temporal trends using simple linear regression. Significance level was set at 5\%. 


\section{Results}

In the State of Rio de Janeiro, according to the cases reported to the Advisory Board on Meningitis from 1994 to 2004, 696 new cases of cryptococcal meningitis were recorded, representing a mean annual incidence rate of 0.45 cases per 100 thousand inhabitants, varying from 0.30 in 1994 to 0.58 per 100 thousand inhabitants in 2003 (Table 1). Gender distribution showed a predominance of males during the study period (male/female ratio: 2.6), with values ranging from $62.3 \%$ in 2000 (male/female ratio: 1.6 ) to $82.4 \%$ in 1995 (male/ female ratio: 4.0) (Table 1). Place of residence was urban in $98.9 \%$ of cases.

Incidence rates according to municipality of residence are shown in the map in Figure 1. Ninety-five percent of cases (656) were observed in the Metropolitan meso-region, with $92.9 \%$ of these in the Rio de Janeiro micro-region. Of the 13 municipalities with reported cases, from the total of 16 in the micro-region, the municipality or city of Rio de Janeiro contributed with more than half $(59.9 \%)$ of the total of 696 cases in the State, followed by Duque de Caxias with 40 cases (7.1\%), Niterói with 42 (6.1\%), São Gonçalo with 33 (4.8\%), São João de Meriti with 31 (4.5\%), and Nova Iguaçu with 29 (4.2\%). Each of the other municipalities had fewer than $2.5 \%$ of the cases. Cases were distributed homogeneously over the months of the year during the study period.

The most frequent diagnostic confirmation for the study period as a whole was culture (42.8\%), followed by direct India ink test (26.3\%) and latex agglutination (23.7\%). Death certificate was the criterion in $6.6 \%$ of cases, autopsy in $0.4 \%$, and therapeutic challenge in $0.1 \%$. Beginning in 2001, there was an upward trend in the proportion of diagnoses by India ink test and by latex agglutination, and beginning in 2003, latex agglutination became the principal confirmatory criterion.

The entire sample of cases showed a mean age of 35.9 years and median of 35 years. There was no significant difference in mean age between genders (males: 36.06; females: 35.48; $\mathrm{p}=0.58$ ). Age ranged from 4 months to 92 years. Age was unknown in four cases. Except for one 89-year-old patient and two 92-year-olds, the maximum age for both genders was 70. Among individuals under 12 years, three were less than a year old (four, six, and eight months), while the others varied from 2 to 11 years, with a mean and median of 6 years. Age distribution remained homogeneous throughout the period.

Analysis of case distribution by age strata according to gender showed that for both males and females, the largest number of cases was in the $30-39$-year bracket, with $41 \%$ of the male cases and $28.4 \%$ of the females. However, when considering the incidence rate per 100 thousand inhabitants, in males the highest rate (1.74) was in this same age bracket (30-39 years), while among females the highest rate (0.45) was in the 40-49year bracket. In the age brackets up to 19 years, the incidence rates were similar $(0.06$ in females and 0.07 in males). In females, the incidence rate in the over-60 bracket was as low as in the brackets up to 19 years (0.07) (Table 2).

Table 1

Percentage distribution of cryptococcal meningitis cases by gender, and incidence rates (per 100,000 inhabitants) from 1994 to 2004.

\begin{tabular}{|c|c|c|c|c|c|c|c|c|}
\hline \multirow[t]{2}{*}{ Year } & \multicolumn{3}{|c|}{ Females } & \multicolumn{3}{|c|}{ Males } & \multicolumn{2}{|c|}{ Total } \\
\hline & $\mathrm{n}$ & $\%$ & Rate & $\mathbf{n}$ & $\%$ & Rate & $\mathbf{n}$ & Rate \\
\hline 1994 & 13 & 32.5 & 0.19 & 27 & 67.5 & 0.42 & 40 & 0.30 \\
\hline 1995 & 12 & 17.6 & 0.17 & 56 & 82.4 & 0.87 & 68 & 0.51 \\
\hline 1996 & 17 & 27.4 & 0.24 & 45 & 72.6 & 0.70 & 62 & 0.46 \\
\hline 1997 & 14 & 20.6 & 0.20 & 54 & 79.4 & 0.83 & 68 & 0.50 \\
\hline 1998 & 12 & 27.3 & 0.17 & 32 & 72.7 & 0.49 & 44 & 0.32 \\
\hline 1999 & 15 & 23.1 & 0.21 & 50 & 76.9 & 0.75 & 65 & 0.47 \\
\hline 2000 & 23 & 37.7 & 0.31 & 38 & 62.3 & 0.55 & 61 & 0.42 \\
\hline 2001 & 25 & 31.6 & 0.33 & 54 & 68.4 & 0.77 & 79 & 0.54 \\
\hline 2002 & 16 & 28.1 & 0.21 & 41 & 71.9 & 0.58 & 57 & 0.39 \\
\hline 2003 & 29 & 33.3 & 0.37 & 58 & 66.7 & 0.81 & 87 & 0.58 \\
\hline 2004 & 14 & 21.5 & 0.18 & 51 & 78.5 & 0.71 & 65 & 0.43 \\
\hline 1994-2004 & 190 & 27.3 & 0.24 & 506 & 72.7 & 0.68 & 696 & 0.45 \\
\hline
\end{tabular}


Cryptococcal incidence rates (per 100,000 inhabitants) by meso-region, micro-region, and municipality in the State of Rio de Janeiro, Brazil, from 1994 to 2004

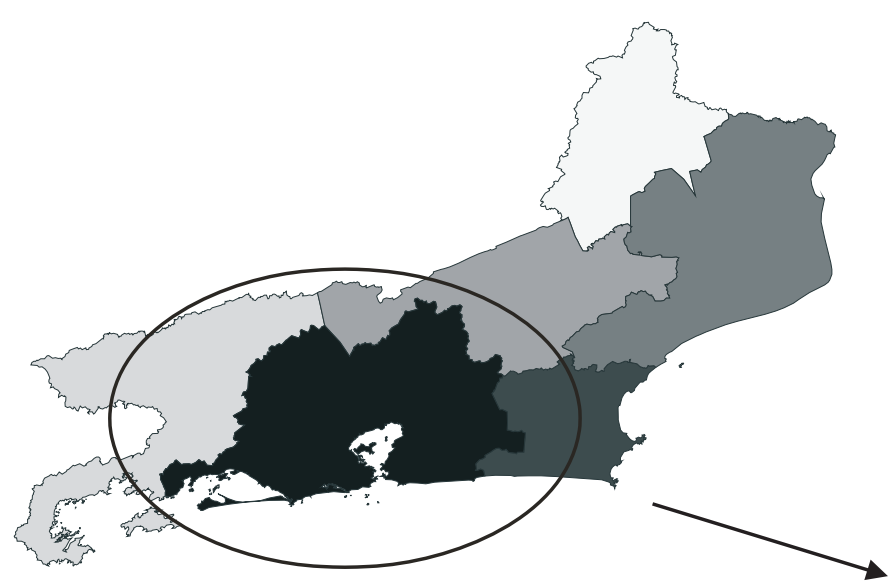

Rio de Janeiro State - Meso-regions

Incidence by meso-region

$\square .03$ - Northwest

0.07 - South

0.12 - Central Region

0.16 - North

0.17 - Baixadas

0.54 - Metropolitan Region of Rio de Janeiro

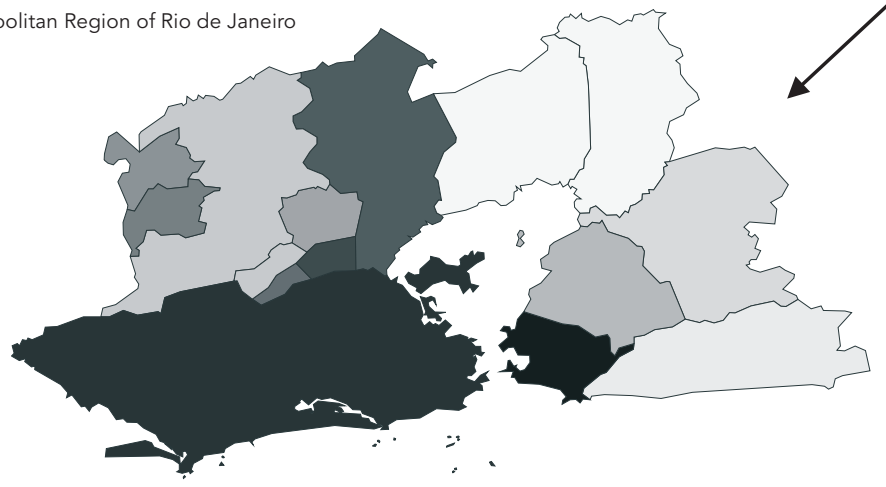

\section{Metropolitan meso-region - Micro-regions}

Incidence by micro-region

0.10 - Macacu-Caceribu

0.12 - itaguaí

0.17 - Serrana

0.25 - Vassouras

0.57 - Rio de Janeiro

0.57 - Rio de Janeiro

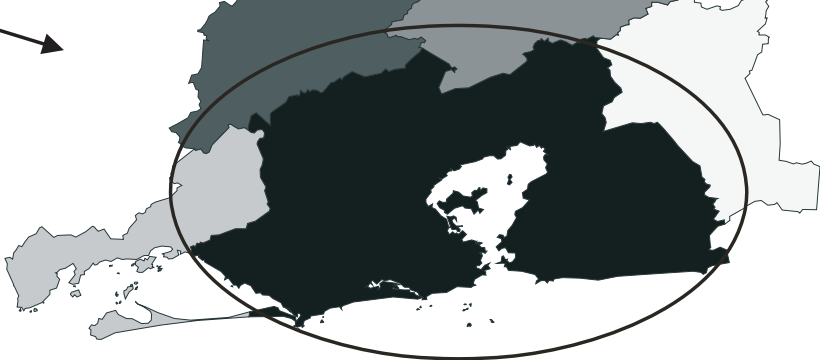

Rio de Janeiro - Municipalities (Countries)

Incidence by municipality

$\square 0.00$ - Guapimirim / Tanguá

0.09 - Magé

D 0.14 - Maricá

0.16 - Itaboraí

0.31 - Nova Iguaçu / Mesquita

0.35 - São Gonçalo

0.36 - Belford Roxo

0.45 - Japeri

0.55 - Queimados

0.59 - Nilópolis

0.60 - Duque de Caxias

0.64 - São João de Meriti

0.67 - Rio de Janeiro

0.83 - Niterói 
Distribution of cryptococcal meningitis cases and incidence rates (per 100,000 inhabitants) by gender for seven age strata from 1994 to 2004.

\begin{tabular}{|c|c|c|c|c|c|c|c|c|c|}
\hline \multirow{3}{*}{$\begin{array}{l}\text { Age } \\
\text { bracket } \\
\text { (years) }\end{array}$} & \multicolumn{3}{|c|}{ Females } & \multicolumn{3}{|c|}{ Males } & \multicolumn{3}{|c|}{ Total } \\
\hline & \multicolumn{2}{|c|}{ Cases } & \multirow[t]{2}{*}{ Rate } & \multicolumn{2}{|c|}{ Cases } & \multirow[t]{2}{*}{ Rate } & \multicolumn{2}{|c|}{ Cases } & \multirow[t]{2}{*}{ Rate } \\
\hline & $\mathbf{N}$ & $\%$ & & $n$ & $\%$ & & $n$ & $\%$ & \\
\hline $0-12$ & 7 & 3.7 & \multirow{2}{*}{0.06 * } & 9 & 1.8 & \multirow{2}{*}{0.07 * } & 16 & 2.3 & \multirow{2}{*}{0.07 * } \\
\hline $13-19$ & 9 & 4.7 & & 11 & 2.2 & & 20 & 2.9 & \\
\hline $20-29$ & 48 & 25.3 & 0.36 & 110 & 21.9 & 0.87 & 158 & 22.8 & 0.61 \\
\hline $30-39$ & 54 & 28.4 & 0.41 & 206 & 41.0 & 1.74 & 260 & 37.6 & 1.05 \\
\hline $40-49$ & 46 & 24.2 & 0.45 & 117 & 23.3 & 1.29 & 163 & 23.6 & 0.85 \\
\hline $50-59$ & 20 & 10.5 & 0.30 & 32 & 6.4 & 0.55 & 52 & 7.5 & 0.42 \\
\hline$\geq 60$ & 6 & 3.2 & 0.07 & 17 & 3.4 & 0.27 & 23 & 3.3 & 0.15 \\
\hline Total & 190 & 100.0 & 0.24 & 502 & 100.0 & 0.68 & 692 & 100.0 & 0.45 \\
\hline
\end{tabular}

* Rate for 0-19 years.

The high proportion of missing data jeopardized the analysis of preexisting diseases. Among the cases reported to the Advisory Board on Meningitis with a diagnosis of cryptococcal meningitis from 1994 to 2004, AIDS was the most frequent preexisting disease, present in 178 patients (25.6\% overall and $98.3 \%$ for cases with information on preexisting disease). When the cryptococcal meningitis database was overlapped with the AIDS reporting data from the SINAN STD/ AIDS database, information on the variable AIDS as preexisting disease reached 426 cases, representing $99.3 \%$ of the cases with information on preexisting disease $(61.2 \%$ of total patients). The percentage of missing information on preexisting disease remained high $35.8 \%$ in males and $45.3 \%$ in females). Except for one case of leukemia in the 30-39-year bracket and two cases of diabetes in the over- 60 bracket, AIDS was the only preexisting disease recorded. The proportion of patients diagnosed with cryptococcal meningitis with AIDS as preexisting disease varied from $47.5 \%$ in 1994 to $72.7 \%$ in 1998 .

Figure 2 shows the AIDS incidence rates (per 100 thousand inhabitants), according to Boletim Epidemiológico AIDST 24, and the cryptococcal meningitis incidence rates from 1994 to 2004 . The incidence adjustment model for the period identified an upward trend in AIDS $(p=0.03)$ and stability in meningitis incidence $(p=0.98)$.

The temporal relationship between meningitis diagnosis and AIDS notification showed concordance with the AIDS notification year for the two events in $59.7 \%$ of cases, while in $16.7 \%$ of the cases meningitis occurred in years prior to AIDS notification, varying from 1 to 4 years prior, while in $23.6 \%$ of cases meningitis occurred after AIDS notification, varying from 1 to 11 years later. In $12.5 \%$ of meningitis cases with AIDS (53 patients), information on the year of AIDS notification was missing.

Of the total of 666 patients with cryptococcal meningitis (95.7\%) in which the outcome was known, 345 (51.8\%) evolved to death from meningitis and $8(1.2 \%)$ to death from another cause. Temporal trend analysis for cryptococcal meningitis case-fatality showed a downward trend during the period, without statistical significance $(\mathrm{p}=0.42)$ (Figure 3).

Case-fatality was high in all age brackets, showing a progressive increase with age: $25 \%$ under 12 years, approximately $47 \%$ in the $13-29$-year bracket, $54 \%$ in the $30-59$-year bracket, and $68 \%$ in the over-60 group. Except for individuals up to 19 years and over 60 , in which the small number of cases precludes evaluation, case-fatality was stable over the period.

Time elapsed between hospitalization and discharge or death varied from 1 to 229 days. Analysis of time of evolution showed that $13 \%$ of the deaths occurred on the first day of hospitalization and $58.7 \%$ during the first 14 days.

Only three percent of patients presented relapse $(n=21)$. Time elapsed between hospital discharge and readmission due to relapse varied from 2 to 45 months, and $90 \%$ of cases with relapse had AIDS. The relapse rate among patients with AIDS was $4.4 \%$. 
Incidence rates (per 100,000 inhabitants) for cryptococcal meningitis and AIDS.

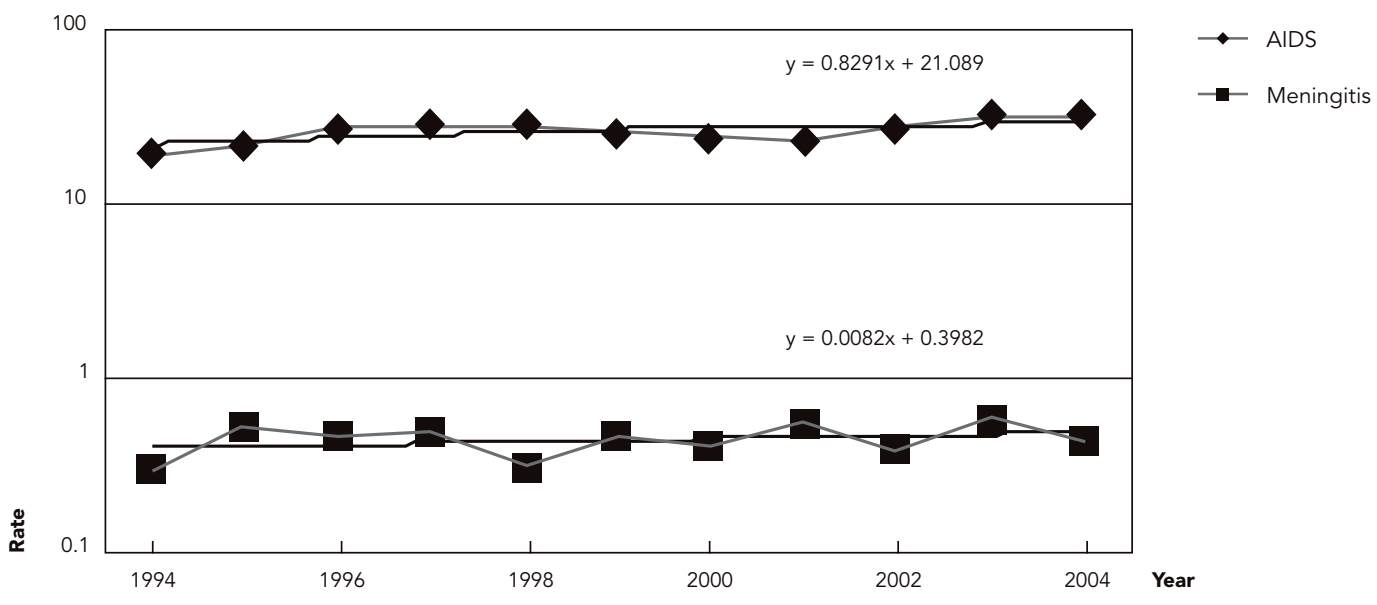

Figure 3

Cryptococcal meningitis case-fatality from 1994 to 2004.

\section{Discussion}

In this study, which aimed to trace the profile of patients with cryptococcal meningitis in the State of Rio de Janeiro, we opted to use the database of the Rio de Janeiro State Advisory Board on Meningitis, since it was more comprehensive than the SINAN database. SINAN only had data on cryptococcal meningitis starting in the year 2000, and from 2000 to 2004, it captured $82 \%$ of the cases reported to the Advisory Board on Meningitis 25 . 
Annual incidence rates in the State were consistent with CDC data that indicates that the annual cryptococcosis incidence rate varies from 0.4 to 1.3 cases per 100 thousand inhabitants. The municipalities with the most cases of cryptococcal meningitis recorded by the Advisory Board on Meningitis coincide with the ones that according to Ministry of Health data 26 showed the most reported AIDS cases during the study period. Considering that HIV infection is still the principal risk factor for cryptococcal disease, this concordance was expected.

Direct CSF microscopy with India ink is the most practical and economical diagnostic method for cryptococcal meningitis, with a sensitivity of $80 \%$ in patients with AIDS and $50 \%$ in HIV-negative patients 27 . Culture is the gold standard 7, but the results are not immediate as are India ink or latex agglutination, since the colonies can only be observed after 48 to 72 hours. If the India ink test is negative and latex agglutination is not performed, this delay until identification of the etiological agent can lead to the meningitis case being classified as "unspecified etiology", in the absence of active surveillance. Sensitivity and specificity in the detection of capsular polysaccharide antigen by latex agglutination depend generally on the kit and vary from $93 \%$ to $100 \%$ and $93 \%$ to $98 \%$, respectively 27 . The increase in the use of latex agglutination as the confirmatory criterion appears to indicate a distortion in the completion of notification forms. Considering the high case-fatality, one can conclude that patients are already quite compromised by the time they reach the health services, and it is unlikely that they would not present a positive culture for Cryptococcus. What may be happening, we believe, is that since the result of latex agglutination is released sooner, it is recorded first on the notification form, without subsequently verifying the result of the culture, which is the gold standard and as such should always be prioritized. Chayakulkeeree \& Perfect 27 use the term "isolated cryptococcal polysaccharidemia" to describe a condition observed in high-risk patients, i.e., extremely immunodepressed, that present a positive cryptococcal antigen titer without positive culture or important symptoms. They conclude that these patients would probably benefit from antifungal therapy to prevent or delay the development of cryptococcosis. However, this does not appear to be the profile of the patients in the Rio de Janeiro State health services, who generally seek (or rather, manage to obtain) treatment when they already display important symptoms.

Our study did not show a decrease in the absolute number of cryptococcal meningitis cases or in the incidence per 100 thousand inhabit- ants over the period, as reported in the literature $8,28,29$. The authors report that this reduction is due to a decline in incidence among HIV-positive patients, since the incidence among HIV-negative patients did not change during the period $8,27,28$. Studies have shown that prophylactic antifungals and especially the advent of HAART have led to a $55 \%$ reduction in absolute cryptococcosis cases in the Netherlands 30 , a $70 \%$ decrease in incidence in the general population in Atlanta 28, a $63 \%$ reduction in incidence in HIV-positive patients in San Francisco 10, and a 46\% drop in HIV-positive individuals in France ${ }^{8}$. Authors of the French study highlight that the decrease occurred mainly in the part of the population with regular access to the health system (Europeans), as opposed to a significant increase among patients with little access to the system (patients of African origin). They conclude that in the postHAART era, lack of diagnosis and/or treatment of HIV infection is associated with increased risk of cryptococcosis. A study by Saraceni et al. 31 on AIDS mortality in Rio de Janeiro from 1995 to 2003 revealed deficient access to HIV diagnosis, impeding the early introduction of HAART, before the development of immune deficiency, as a basis for the occurrence of opportunistic infections. They highlight that patients frequently come to emergency services without knowledge of their HIV infection and already presenting opportunistic infections. In Brazil, data from the Emílio Ribas Institute in São Paulo showed a reduction in cryptococcal meningitis in AIDS patients, from $7.7 \%$ in 1995 to $3.1 \%$ in 2002 7. At the Evandro Chagas Clinical Research Institute, Oswaldo Cruz Foundation, in Rio de Janeiro, Pinto Jr. 32 observed a reduction (from $7.6 \%$ in $1987-1994$ to $1.8 \%$ in 1999-2002) in the incidence of cryptococcal meningitis among AIDS patients. These data appear to indicate that in patients monitored by well-structured services, allowing early access to HAART, there can be an important reduction in cryptococcosis, at rates similar to those reported in the international literature. Our study showed $61.2 \%$ of cryptococcosis patients with HIV infection. However, despite the harmonization with the SINAN STD/AIDS database, some patients may not have been identified due to limitations in the data cross-analysis and the existing underreporting in the STD/AIDS database itself 33 . Thus, it was not possible to conduct a segmentation for AIDS, comparing it with non-AIDS, which would have allowed us to make inferences for each of these segments, including for the role of HAART.

In relation to other preexisting diseases, only three cases referred to other predisposing conditions for cryptococcal disease: leukemia 
(one) and diabetes (two). We believe that lack of investigation of preexisting diseases, as we verified in relation to AIDS, is responsible for this low number of patients with other predisposing conditions. The importance of other conditions has increased in the last 10 to 15 years 5 , especially in developed countries where there has been extensive development in the field of transplants and immune-manipulating therapies 27 . The international literature reports percentages as high as $74.6 \% 8$ or $82 \% 28$ for the presence of underlying conditions like diabetes or cancer in patients without HIV infection. In Brazil, different authors highlight the relevance of predisposing conditions for the development of cryptococcal meningitis. Livramento et al. 34 , for the period from 1984 to 1992 , observed some predisposing condition in $60 \%$ of cryptococcal meningitis patients without HIV infection, with renal transplant as the most frequent (73.3\%), and Carvalho 17 , for the period from 1980 to 2000 , reported $78.3 \%$ of cases having predisposing conditions, mainly diabetes and cancer. The series by Rozenbaum \& Gonçalves 20 in the State of Rio de Janeiro (1960 to 1989) showed $29.6 \%$ of cases with another predisposing condition among patients without AIDS, half of whom in use of immune suppressing drugs.

Predominance of male gender has been reported consistently in cryptococcal disease 35 . In the early AIDS epidemic, the number of male cases of cryptococcosis reached eight times that of females, accompanying the HIV infection profile. In recent years, with the increase in AIDS among women, the distribution between the sexes is changing 5 . Our study showed a male/female ratio of 2.6:1, close to the $2: 1$ ratio in the State of do Rio de Janeiro during the same period for AIDS, the principal risk factor for cryptococcosis. The fact that we did not observe a difference in the mean age between men and women, unlike reports from the literature, in which female cases are significantly younger 5,8 , mirroring the age profile for HIV infection, could be explained by the persistent increase observed since 1998 in AIDS incidence among Brazilian women over 24 years of age 36 .

In our study, $2.3 \%$ of patients were in the under-12-year bracket and $25 \%$ had AIDS as a known preexisting disease. In the series by Rozembaum \& Gonçalves 20 from 1960 and 1989, $1.8 \%$ of the patients $(3 / 171)$ were under 12 years of age, one of whom had AIDS. In pediatric patients with AIDS, Py et al. 22 in Rio de Janeiro observed $8.3 \%$ of cases of cryptococcal meningitis. In Brazil, cryptococcal meningitis in children has been well studied in the Northeast Region, where C. gattii is endemic. Thus, Martins 18 in
53 cases under 14 years of age, Corrêa et al. 21 in 19 cases under 13 years, and Cavalcanti 37 in 17 cases under 10 years and 27 from 11 to 20 years of age found no cases of AIDS and observed a significant predominance of isolation of $C$. gattii. According to the international literature, cryptococcosis is rare in childhood 1 , and the proportion of cryptococcal disease among children with HIV is much lower than in adults 12 . Abadi et al. 23 observed $1.4 \%$ prevalence of cryptococcal infection in American children with AIDS from 1985 to 1996. During this same period, data from studies in Europe and the United States reported $2.9 \%$ and $13.3 \%$ prevalence, respectively, in adults 11 . Goldman et al. 38 , with the objective of determining whether the low prevalence of cryptococcal disease in childhood is due to low exposure to Cryptococcus, analyzed serum samples from 185 children in the Bronx, New York City, and observed that for the majority, age at seroconversion was under ten years. Based on their results, they concluded that the low incidence of cryptococcosis in children with AIDS is not due to lack of exposure to the agent. Dromer et al. 8 reported $0.9 \%$ of patients younger than 15 years among 2,125 cases of cryptococcal infection from 1985 to $2001,31 \%$ of whom were HIV-positive and $31 \%$ immunosuppressed. Chen et al. 1, from 1994 to 1998 , observed $0.6 \%$ of children among 350 patients with cryptococcal infection. The high percentage of children with cryptococcosis in our study and also reported by Py et al. 22 as compared to the international literature could result from greater environmental pressure for exposure to both species of Cryptococcus, both in patients with HIV infection and in immunocompetent patients.

We did not observe a change in case-fatality from cryptococcal meningitis during the period studied. In Brazil, cryptococcosis case-fatality with or without underlying disease ranges from $45 \%$ to $65 \% 7,17,39$. In the series by Rozembaum \& Gonçalves 20 in Rio de Janeiro from 1960 to 1989 , overall case-fatality in the sample was $52.3 \%$ (65.7\% in AIDS patients, $38.6 \%$ in non-immune suppressed patients, and $36.8 \%$ in patients with other predisposing conditions). Case-fatality greater than $40 \%$ is close to that observed in African countries 11. For AIDS, the principal risk factor for cryptococcosis, a reduction in case-fatality was observed in the State of Rio de Janeiro beginning in 1997, shortly after the introduction of HAART, with subsequent stabilization beginning in 1999 36. Evidence suggests that combination antiretroviral treatment can also alter the evolution of AIDS-associated conditions, since this treatment partially recovers the patient's immune defenses 9 . 
We observed a low relapse rate, which may suggest the efficacy of adequate maintenance therapy, equaling international standards 40,41 . However, considering the precarious state of health services, we cannot rule out the possibility that the surveillance system is failing to detect cases of relapse. According to Mamidi et al. ${ }^{42}$, even after effective initial treatment, relapse occurs in $25 \%$ to $60 \%$ of HIV-infected patients with cryptococcal meningitis if a maintenance regimen is not implemented. This regimen, proposed by the Infectious Diseases Society of America, consists of the administration of an antifungal agent for one year in patients without HIV infection, and in those with AIDS, administration of an antifungal for at least two years and suspension if there is sustained immune recovery with HAART 27,43 . With the introduction of maintenance therapy, the risk of relapse dropped to values ranging from $2 \%$ to $4 \% 39,40$.

Two key aspects should be considered when analyzing the results of this study: underreporting of cases in the epidemiological surveillance system and the high number of patients with unknown preexisting disease. The underreporting of various diseases is well known in Brazil 33,36 and should always be taken into consideration. As for cryptococcal meningitis, an active search showed $24.4 \%$ of cases not recorded by the Ad-

Resumo

Este artigo objetivou determinar o perfil epidemiológico da meningite criptocócica no Estado do Rio de Janeiro, Brasil, no período de 1994 a 2004. Um total de 696 casos novos foi registrado, representando uma taxa de incidência média anual de 0,45 casos por 100 mil habitantes. Houve predominância do sexo masculino, a média de idade foi de 35,9 anos, a AIDS foi praticamente a única enfermidade preexistente registrada, estando presente em $61,2 \%$ do total de pacientes, e a letalidade foi de 51,8\%. No período estudado, a taxa de incidência manteve-se estável. A AIDS ainda é a principal condição predisponente e, assim, o perfil da maioria dos pacientes acompanha o daqueles infectados pelo HIV. A avaliação de outras doenças preexistentes ficou prejudicada pela falta de informação.

Meningite Criptocócica; Taxa de Incidência; Vigilância Epidemiológica visory Board on Meningitis from 2000 to 200425. As for preexisting diseases, in conditions like cryptococcosis, in which the underlying diseases that affect cellular immunity play a central role, missing information hinders the identification of patients at risk and negatively affects risk factor assessment over time. The proportion we managed to detect of cryptococcal meningitis cases with HIV (61.2\%) is close to the $63 \%$ observed by Livramento et al. 34 in São Paulo from 1984 to 1992, but is lower than reported by Carvalho 17 in Ribeirão Preto from 1980 to 2000 , where $73.1 \%$ of patients with cryptococcosis were HIV-positive. Missing information also prevents the evaluation of cryptococcosis incidence in immunocompetent patients.

The exploratory analysis of the database from the Advisory Board on Meningitis at the Rio de Janeiro State Health Department, although subject to the limitations discussed above, allowed an evaluation of the trends in cryptococcal meningitis in the State. The incidence adjustment model for the period identified stability in meningitis incidence. AIDS is still the greatest risk factor, and thus the profile for the majority of patients accompanies that of HIV-infected individuals. Meanwhile, missing information jeopardizes the evaluation of other preexisting diseases and cryptococcosis in immunocompetent individuals.

\section{Contributors}

B. C. Q. Leimann was responsible for the literature review, data analysis, and organization and writing of the article. R. J. Koifman contributed to the data analysis and organization and writing of the article.

\section{Acknowledgments}

The authors wish to thank the Rio de Janeiro State Health Department for kindly providing access to the data. 


\section{References}

1. Chen S, Sorrell T, Nimmo G, Speed B, Currie B, Ellis $\mathrm{D}$, et al. Epidemiology and host- and variety-dependent characteristics of infection due to Cryptococcus neoformans in Australia and New Zealand. Clin Infect Dis 2000; 31:499-508.

2. Kwon-Chung KJ, Varma A. Do major species concepts support one, two or more species within Cryptococcus neoformans? FEMS Yeast Res 2006; 6:574-87.

3. Nishikawa MM, Lazera MS, Barbosa GG, Trilles L, Balassiano BR, Macedo RCL, et al. Serotyping of 467 Cryptococcus neoformans isolates from clinical and environmental sources in Brazil: analysis of host and regional patterns. J Clin Microbiol 2003; 41:73-7.

4. Oliveira-Netto IC, Machado CC, Wagner MB, Severo LC. Meio século de criptococose no Brasil: revisão de 308 casos (1941-1992). Âmbito Hosp 1993; 7:5-16.

5. Tintelnot K, Lemmer K, Losert H, Schär G, Polak A Follow-up of epidemiological data of cryptococcosis in Austria, Germany, and Switzerland with special focus on the characterization of clinical isolates. Mycoses 2004; 47:455-64.

6. Lacaz CS, Porto E, Martins JEC, Heins-Vaccari, Melo NT. Criptococose. In: Lacaz CS, Porto E, Martins JEC, Heins-Vaccari EM, Melo NT, organizadores. Tratado de micologia médica Lacaz. São Paulo: Editora Sarvier; 2002. p. 416.

7. Pappalardo MCSM, Melhem MSC. Cryptococcosis: a review of the Brazilian experience for the disease. Rev Inst Med Trop São Paulo 2003; 45:299-305.

8. Dromer F, Mathoulin-Péllissier S, Fontanet A, Ronin O, Dupont B, Lortholary O. Epidemiology of HIV-associated cryptococcosis in France (19852001): comparison of the pre- and post-HAART era. AIDS 2004; 18:555-62.

9. Guimarães MDC. Estudo temporal das doenças associadas à AIDS no Brasil, 1980-1999. Cad Saúde Pública 2000; 16 Suppl 1:S21-36.

10. Manfredi R, Pieri F, Pileri AS. The changing face of AIDS related opportunism: cryptococcosis in the highly active antiretroviral therapy (HAART) era. Case reports and literature review. Mycopathologia 1999; 148:73-8.

11. Perfect JR, Casadevall A. Cryptococcosis. Infect Dis Clin North Am 2002; 16:837-74.

12. Division of Bacterial and Mycotic Diseases, Centers for DiseaseControland Prevention. Cryptococcosis. http://www.cdc.gov/ncidod/dbmd/diseaseinfo/ cryptococcosis_t.htm (accessed on Dec/2005).

13. Chrétien F, Lortholary O, Kansau I, Neuville S, Gray F, Dromer F. Pathogenesis of cerebral Cryptococcus neoformans infection after fungemia. J Infect Dis 2002; 186:522-30.

14. Fessler RD, Sobel J, Guyot L, Crane L, Vazquez J, Szuba J, et al. Management of elevated intracranial pressure in patients with Cryptococcal meningitis. J Acquir Immune Defic Syndr Hum Retrovirol 1998; $17: 137-42$.
15. Hamill RJ. Cryptococcosis. In: Tierney LM, McPhee SJ, Papadakis M, editors. Current medical diagnosis and treatment. 42nd Ed. New York: Lange Medical Books/MacGraw-Hill; 2003. p. 1487-8.

16. Hajjeh RA, Conn LA, Stephens DS, Baughman W, Hamill R, Graviss E, et al. Cryptococcosis: population-based multistate active surveillance and risk factors in human immunodeficiency virus-infected persons. Cryptococcal Active Surveillance Group. J Infect Dis 1999; 179:449-54.

17. Carvalho FS. Estudo comparativo da criptococose em pacientes aparentemente imunocompetentes, com SIDA ou com outras formas de imunodeficiência [Masters Thesis]. Ribeirão Preto: Faculdade de Medicina de Ribeirão Preto, Universidade de São Paulo; 2003.

18. Martins LMS. Epidemiologia da criptococose em crianças e diversidade da Cryptococcus neoformans no meio norte do Brasil [Masters Thesis]. Rio de Janeiro: Instituto Oswaldo Cruz, Fundação Oswaldo Cruz; 2003.

19. Gonçalves AJR, Lopes PFA, Pinto AMM, Lazera M, Menezes JA, Cunha RQ, et al. Criptococose: estudo de 27 casos observados no Hospital dos Servidores do Estado - INAMPS e no Hospital São Sebastião - Rio de Janeiro. J Bras Med 1984; 46:43-63.

20. Rozembaum R, Gonçalves AJ. Clinical epidemiological study of 171 cases of cryptococcosis. Clin Infect Dis 1994; 18:369-80.

21. Corrêa MPSC, Oliveira EC, Duarte RRBS, Pardal PPO, Oliveira FM, Severo LC. Criptococose em crianças no estado do Pará, Brasil. Rev Soc Bras Med Trop 1999; 32:505-8.

22. Py EA, Aloe M, Burlamaqui L, Guasti S, Monerat PJT. Relato de cinco casos de meningite criptocócica em crianças com a síndrome da imunodeficiência adquirida (AIDS). Arq Bras Pediatr 1997; 4:15-20.

23. Abadi J, Nachman S, Kressel AB. Cryptococcosis in children with AIDS. Clin Infect Dis 1999; 28:309-13.

24. Dados epidemiológicos - AIDS. Tabela II. Taxa de incidência (por 100.000 hab.) de AIDS segundo UF de residência por ano de diagnóstico, Brasil, 19942004. Boletim Epidemiológico AIDST 2005; Ano II, no. 1. p. 25.

25. Leimann BCQ. Epidemiologia da meningite criptocócica no Estado do Rio de Janeiro no período de 1994 a 2004 [Masters Thesis]. Rio de Janeiro: Escola Nacional de Saúde Pública, Fundação Oswaldo Cruz; 2007.

26. Ministério da Saúde. Casos de AIDS identificados no Rio de Janeiro. http://www.aids.gov.br/cgi/tab cgi.exe?tabnet/RJ.def (accessed on Nov/2006).

27. Chayakulkeeree M, Perfect JR. Cryptococcosis. Infect Dis Clin North Am 2006; 20:507-44, v-vi.

28. Mirza SA, Phelan M, Rimland D, Graviss E, Hamill R, Brandt ME, et al. The changing epidemiology of cryptococcosis: an update from population-based active surveillance in 2 large metropolitan areas, 1992-2000. Clin Infect Dis 2003; 36:789-94. 
29. Friedman GD, Jeffrey Fessel W, Udaltsova NV, Hurley LB. Cryptococcosis: the 1981-2000 epidemic. Mycoses 2005; 48:122-5.

30. van Elden LJR, Walenkamp AME, Lipovsky MM, Reiss P, Meis JFGM, Marie S, et al. Declining number of patients with cryptococcosis in the Netherlands in the era of highly active antiretroviral therapy. AIDS 2000; 14:2787-8.

31. Saraceni V, Cruz MM, Lauria LM, Durovni B. Trends and characteristics of AIDS mortality in the Rio de Janeiro city after the introduction of highly active antiretroviral therapy. Braz J Infect Dis 2005; 9:209-15.

32. Pinto Jr. VL. Criptococose associada à AIDS: análise da casuística do Instituto de Pesquisa Clínica Evandro Chagas-Fiocruz entre 1987 e 2002 [Masters Thesis]. Rio de Janeiro: Fundação Oswaldo Cruz; 2003.

33. Ferreira NMB, Portela MC, Vasconcellos MTL. Fatores associados à subnotificação de pacientes com AIDS, no Rio de Janeiro. Rev Saúde Pública 2000; 34:170-7.

34. Livramento JA, Machado LR, Nóbrega JPS, Gomes HR, Vianna LS, Spina-França A. CSF in 85 patients with AIDS and CNS cryptococcosis. Arq Neuropsiquiatr 1992; 50:491-6.

35. Mitchell TG, Perfect JR. Cryptococcosis in the era of AIDS - 100 years after the discovery of Cryptococcus neoformans. Clin Microbiol Rev 1995; 8:515-48.

36. Chequer P. Apresentação. Boletim Epidemiológico AIDST 2005; Ano II, nº. 1. p. 3.
37. Cavalcanti MAS. Criptococose sistêmica endêmica pela variedade gattii no meio norte do Brasil [Doctoral Dissertation]. Teresina: Universidade Federal do Piauí; 1997.

38. Goldman DL, Khine H, Abadi J, Lindenberg BS, Pirofski LA, Niang R, et al. Serologic evidence for Cryptococcus neoformans infection in early childhood. Pediatrics 2001; 107:E66.

39. Moreira TA, Ferreira MS, Ribas RM, Borges AS. Criptococcose: estudo clínico-epidemiológico, laboratorial e das variedades do fungo em 96 pacientes. Rev Soc Bras Med Trop 2006; 39:255-8.

40. Lortholary O, Poizat G, ZellerV, Neuville S, Boibieux A, Alvarez M, et al. Long-term outcome of AIDS-associated cryptococcosis in the era of combination antiretroviral therapy. AIDS 2006; 20:2183-91.

41. Saag M, Graybill RJ, Larsen RA. Practical guidelines for the management of cryptococcal disease. Clin Infec Dis 2000; 30:710-8.

42. Mamidi A, DeSimone JA, Pomerantz RJ. Central nervous system infections in individuals with HIV1 infection. J Neurovirol 2002, 8:158-67.

43. Benson CA, Kaplan JE, Masur H, Pau A, Holmes KK; Centers for Disease Control and Prevention, et al. Treating opportunistic infections among HIV-infected adults and adolescents: recommendations from CDC, the National Institutes of Health, and the HIV Medicine Association/Infectious Diseases Society of America. MMWR Recomm Rep 2004; 53(RR-15):1-112.

Submitted on 12/Apr/2007

Final version resubmitted on 15/Oct/2007 Approved on 08/Nov/2007 